\title{
Genetic Analysis in Streptomyces chrysomallus
}

\author{
By ULLRICH KELLER, * ULRIKE KRENGEL AND ANGELA HAESE \\ Institut für Biochemie und Molekulare Biologie, Technische Universität Berlin, Franklinstraße 29, \\ D1000 Berlin 10, FRG
}

(Received 18 July 1984; revised 5 December 1984)

A circular linkage map was developed for Streptomyces chrysomallus, a producer of actinomycin C. The map order of various marker loci was deduced from matings and to a minor extent from protoplast fusions. The map strongly resembles that of Streptomyces coelicolor A3(2). The recombination frequencies were low and highly variable (from $10^{-9}$ to $5 \times 10^{-6}$ ). Plasmid pIJ303 expressed its thiostrepton resistance gene in $S$. chrysomallus but did not promote chromosomal transfer or induce the $\mathrm{Ltz}^{+}$phenotype. The data provide a background of genetics for investigations of antibiotic synthesis in this strain.

\section{INTRODUCTION}

Streptomyces chrysomallus produces actinomycins, bicyclic chromopeptide lactone antibiotics, the synthesis of which is widespread among actinomycetes (Katz, 1967). Recent biochemical studies with $S$. chrysomallus and Streptomyces antibioticus revealed that 4-methyl-3hydroxyanthraniloyl pentapeptide lactones are the immediate precursors of actinomycins. In addition, a 4-methyl-3-hydroxyanthranilic acid (4-MHA) activating enzyme, most probably involved in actinomycin synthesis, could be isolated from $S$. chrysomallus (Keller, 1984; Keller $e t$ $a l ., 1984)$. These results, and current biochemical work on pentapeptide lactone synthesis in this laboratory, make $S$. chrysomallus an obvious candidate for genetic studies on the synthesis of these antibiotics. Such genetic work may involve the characterization of mutants with blocks in the synthetic pathway by complementation analyses and screening for specific enzyme defects. In addition, mapping studies could add information about the number of genes involved and also about their location on the chromosome, as has been shown in the cases of actinorhodin and undecylprodigiosin synthesis in Streptomyces coelicolor A3(2) (Rudd \& Hopwood, 1979, 1980). As a prerequisite for such studies a background of genetics must be available. In this paper we describe the construction of a circular linkage group of $S$. chrysomallus with a limited number of marker loci.

\section{METHODS}

Media. Complete medium (CM) for maintenance of strains and for mutant isolation was a modification of that of Pridham et al. (1956/57). It contained (per litre): $5 \mathrm{~g}$ malt extract (Wander, Bern, Switzerland), $5 \mathrm{~g}$ yeast extract (Difco), $5 \mathrm{~g}$ maltose (Serva, Heidelberg, FRG) and $15 \mathrm{~g}$ agar (Oxoid no. 3), and was adjusted to $\mathrm{pH} 7.5 \mathrm{with} 1 \mathrm{M}$ $\mathrm{NaOH}$.

Minimal medium (MM) was the same as that described by Hopwood (1967), except that glucose was substituted by $0.5 \%(w / v)$ maltose. Maltose was autoclaved separately as a $25 \%(w / v)$ solution and added to the medium before cooling. Nutritional requirements were added in concentrations as described previously (Friend \& Hopwood, 1971). Regeneration medium for protoplast fusion cultures was based on R 2 medium and contained $0 \cdot 25 \mathrm{M}$-sucrose (Keller $e t$ al., 1983). Since many of the strains used regenerated with frequencies of less than $0 \cdot 1 \%$, fusion cultures were routinely regenerated in the additional presence of $0.5 \%$ yeast extract (Thompson et al., 1980), which increased the regeneration frequencies of many strains by a factor of 5-100. The same medium was also used for the regeneration of protoplasts transformed with plasmid DNA. Soft regeneration agar for the selection of

Abbreviation: MM, minimal medium. 
Table 1. Auxotrophic markers

\begin{tabular}{ll} 
Marker & \multicolumn{1}{c}{ Requirements } \\
ade-1 & Adenine or guanine \\
arg-1 & $\begin{array}{c}\text { Arginine, citrulline or ornithine } \\
\text { (non-allelic with } \arg -8 \text { ) }\end{array}$ \\
arg-2 & Arginine \\
arg-8 & Arginine, citrulline or ornithine \\
cys-1 & Cysteine \\
his-1 & Histidine or histidinol \\
ih $r-1$ & Isoleucine + valine \\
let -1 & Leucine \\
met-4 & Methionine or homocysteine
\end{tabular}

Marker

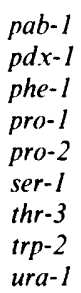

pab-l

$p d x-1$

phe-l

pro-2

ser-I

thr -3

ura-l

\section{Requirements}

p-Aminobenzoic acid

Pyridoxine

Phenylalanine

Proline

Proline

Serine

Threonine

Tryptophan

Uracil

transformants contained thiostrepton $\left(25 \mu \mathrm{g} \mathrm{ml}^{-1}\right.$ final concentration) or neomycin $\left(20 \mu \mathrm{g} \mathrm{ml}^{-1}\right)$ and was a mixture of the regeneration medium and protoplast buffer $\mathrm{P}$ medium (Okanishi et al., 1974) in a ratio of $1: 1$

Strains. All strains of $S$. chrysomallus, bearing up to five auxotrophic markers, were derived from strain ATCC 11523. They were maintained on CM slants or kept as spore suspensions in $30_{0}^{\circ}(\mathrm{v} / \mathrm{v})$ glycerol at $-20^{\circ} \mathrm{C}$.

Mutagenic treatments. Mutant strains were isolated after treatment of spore suspensions either with UV light at $254 \mathrm{~nm}$ or by exposure to $N$-methyl- $N^{\prime}$-nitro- $N$-nitrosoguanidine (NTG) as described previously (Delić et al., 1970). Mutagenesis with ethylmethane sulphonate (EMS) was effective when spores were suspended in $30 \%$ glycerol containing $5 \mathrm{mg} \mathrm{ml}^{-1}$ of the mutagen.

Genetic markers. Treatment of $S$. chrysomallus spores with any of the three mutagens yielded only a limited number of auxotrophic phenotypes; the characteristics of the auxotrophic markers used in this study are shown in Table 1. Since the viability of mutants very often decreased from one mutagenic step to the next, nearly all strains bearing more than two markers were constructed by recombination.

Crosses. Generally, strains to be crossed differed from each other by at least two characters. Before crossing, the strains were tested for their genotype and reversion rate. Each strain was streaked separately on four or five slants $(25 \times 150 \mathrm{~mm})$ of appropriately supplemented MM. After growth for $4-6 \mathrm{~d}$ at $28-30^{\circ} \mathrm{C}, 6 \mathrm{ml}$ sterile water was added to each slant and the agar surface was carefully scraped into the water with a loop. The resulting suspensions of spores and mycelial clumps were poured into screw-cap vials and vortexed vigorously. After filtration through cotton wool the spore suspensions of each strain were combined and centrifuged ( $5000 \mathrm{~g}$ for $15 \mathrm{~min}$ ). The pelleted spores were resuspended in $2-3 \mathrm{ml}$ sterile water. Portions of the spore suspensions from the two parental strains were mixed in an approximate ratio of $1: 1$ (estimated by optical density at $650 \mathrm{~nm}$ ) and $0 \cdot 1 \cdot 0 \cdot 2 \mathrm{ml}$ of the mixed suspension was inoculated onto each of 16-24 slants of fully supplemented MM (i.e. with all parental requirements). Alternatively, in the case of poorly sporulating strains, Petri dishes with the same medium were used. The large number of slants or plates in each cross was necessary in order to obtain enough spores: $S$. chry:somallus does not sporulate well and has a rather low fertility.

Crosses by protoplast fusion were performed as described previously (Keller et al., 1983). Because of the much higher recombination frequencies compared to those of matings, one or two regeneration plates were sufficient for recovery of large numbers of recombinants.

Isolation and analysis of recombinants. Cross slants or plates were incubated for $6 \mathrm{~d}$ at $28-30{ }^{\circ} \mathrm{C}$ and spores were isolated as described above. The purified and combined spores were suspended in $2-3 \mathrm{ml}$ water $\left(10^{9}-10^{11}\right.$ c.f.u. $)$ and tenfold dilutions were made up to $10^{-11}$. Samples $(0 \cdot 1 \mathrm{ml})$ from dilutions $10^{-1}-10^{-+}$were plated in duplicate on plates containing selective media, and from dilutions $10^{-4}-10^{-11}$ on parental media. Undiluted samples $(0 \cdot 1 \mathrm{ml})$ of the original suspension were also plated on five plates of each selective medium because the fertility of crosses could be very low (see Results). The plates were incubated for $3 \mathrm{~d}$ and colonies on selective media were transferred to plates of the same medium with sterile toothpicks. After incubation for 1 week these master plates were replica plated onto diagnostic media for genotype identification. Heterokaryons among these samples could easily be recognized by their failure to grow on the same selective medium from which they had been isolated; they usually represented less than $10 \%$ of the total non-parental colonies, and their frequencies depended on the length of the selected interval (see Results). Successful crosses usually yielded 200-4000 recombinants per cross, representing recombination frequencies of between $10^{-9}$ and $5 \times 10^{-6}$.

Introduction of plasmid DNA into $S$. chrysomallus by transformation. The plasmids pIJ303 and pIJ211 (kindly provided by Professor D. A. Hopwood, Norwich, UK) were introduced into several genetically marked strains of $S$. chrysomallus. Isolation of pIJ303 and pIJ211 from their Streptomyces lividans hosts, PEG-mediated transformation, and selection of transformants was done essentially as described by Chater et al. (1982). 
Table 2. Analysis of a four-factor cross of S. chrysomallus strains E1 (arg-8 ser-1) and R24 (leu-1 phe-1)

The four-factor cross was done following the procedure of Hopwood (1972).

\begin{tabular}{|c|c|c|c|c|}
\hline \multirow{2}{*}{$\begin{array}{c}\text { Genotypes of } \\
\text { selectable } \\
\text { progeny }\end{array}$} & \multicolumn{4}{|c|}{$\begin{array}{l}\text { Frequencies of genotypes recovered on selective media } \\
\text { supplemented with: }\end{array}$} \\
\hline & $\mathrm{Arg}+\mathrm{Leu}$ & Arg + Phe & Ser + Leu & Ser + Phe \\
\hline++++ & 89 & 94 & 85 & 78 \\
\hline $\arg +++$ & 11 & 10 & - & - \\
\hline+ leu ++ & 92 & - & 57 & - \\
\hline$++\operatorname{ser}+$ & - & - & 26 & 18 \\
\hline+++ phe & - & 5 & - & 4 \\
\hline $\operatorname{argleu}++$ & 8 & - & - & - \\
\hline++ ser phe & - & - & - & 1 \\
\hline arg ++ phe & - & 1 & - & - \\
\hline+ leu ser + & - & - & 2 & - \\
\hline $\begin{array}{l}\text { Total no. of } \\
\text { recombinants } \\
\text { per plate }\end{array}$ & 200 & 110 & 170 & 101 \\
\hline $\begin{array}{l}\text { No. of } \\
\text { recombinants } \\
\text { examined }\end{array}$ & 250 & 249 & 249 & 250 \\
\hline
\end{tabular}
Mean frequency of each pair of complementary genotypes

$86 \cdot 5$

$10 \cdot 5$

$74 \cdot 5$

22

$4 \cdot 5$

$4 \cdot 5$

$1 \cdot 5$

Relative recombination frequency in each interval (including the corresponding values from Tables 3 and 4$)$ :

$\begin{array}{lcccccc} & \text { arg-8-leu-1 } & \text { arg-8-phe-1 } & \text { ser-1-leu-l } & \text { ser-1-phe-1 } & \text { arg-8-ser-1 } & \text { leu-1-phe-1 } \\ \text { Table 2 } & 117.5 & 184.5 & 103.0 & 176.0 & 38.5 & 85.0 \\ \text { Table 3 } & 28 & 84 & 17 & 89 & 13 & 88 \\ \text { Table 4 } & 62.0 & 179.5 & 58.5 & 177.0 & 16.5 & 203.5\end{array}$

\section{RESULTS}

\section{Mapping of four marker-loci by four-factor crosses}

Establishing a genetic map of a new streptomycete is commonly initiated by determining the arrangement of four markers in four-factor crosses by the procedure of Hopwood (1972). In such crosses, spores from mixed cultures of two double auxotrophs are seeded onto four selective media, each containing two requirements in non-parental combinations. By genotype analysis of haploid recombinants recovered from the selective media, it is possible to deduce the arrangement of the markers involved. Tables 2, 3 and 4 show the results of three sets of fourfactor crosses between double auxotrophs of $S$. chrysomallus, involving the mutations arg- 8 , leu-l, phe-l and ser- 1 . In each cross these four markers were present in different parental combinations. This was possible because all four doubly auxotrophic complementary recombinant genotypes were recovered from the first cross (Table 2). In each cross the frequencies of recombinants of a particular genotype recovered on the four different media did not differ greatly from each other, and this also applied to the frequencies of the members of the two pairs of complementary genotypes. These are prerequisites for the analysis. From the numbers of classes of complementary genotypes on the different media, the average frequencies could be calculated (final column in Tables 2, 3 and 4). From these average frequencies, the relative recombination frequencies between the six pairs of markers in each cross was derived (lower part of Table 2).

In all three crosses the frequency of recombination in the arg-8-ser-1 interval had the lowest value, whereas the intervals arg- $8-$ phe- $I$ and ser- 1 -phe- $I$ had high values. The intervals ser- 1 $l e u-l$ and $a r g-8-l e u-I$ showed intermediate values. The interval leu-l-phe- 1 had high values in Tables 3 and 4 . From the relative recombination frequencies, two possible marker arrangements could be deduced, as shown in Fig. 1. Following the procedure of Baumann et al. (1974) the 
Table 3. Analysis of a four-factor cross of $S$. chrysomallus strains $R 74$ (arg-8 phe-1) and R75 (leu-1 ser-1)

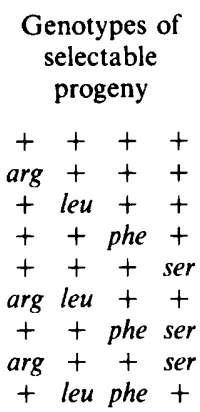

Total no. of

recombinants per plate

No. of recombinants examined
Frequencies of genotypes recovered on selective media supplemented with:

$\begin{array}{cccc}\text { Arg + Leu } & \text { Arg + Ser } & \text { Phe + Leu } & \text { Phe+Ser } \\ 10 & 7 & 6 & 9 \\ 75 & 69 & - & - \\ 1 & - & 3 & - \\ - & - & - & 8 \\ - & 8 & - & - \\ 8 & - & - & - \\ - & - & 0 & - \\ - & 0 & 10 & 30 \\ - & - & & \\ 94 & 84 & 246 & 245 \\ 250 & 248 & & \end{array}$

Mean frequency of each pair of complementary genotypes

Table 4. Analysis of a four-factor cross of S. chrysomallus strains $R 73$ (arg-8 leu-1) and R76 (phe-1 ser-1)

\begin{tabular}{|c|c|c|c|c|}
\hline \multirow{2}{*}{$\begin{array}{l}\text { Genotypes of } \\
\text { selectable } \\
\text { progeny }\end{array}$} & \multicolumn{4}{|c|}{$\begin{array}{l}\text { Frequencies of genotypes recovered on selective media } \\
\text { supplemented with: }\end{array}$} \\
\hline & Arg + Phe & $\mathrm{Arg}+\mathrm{Ser}$ & Leu + Phe & Leu + Ser \\
\hline++++ & 3 & 9 & 3 & 6 \\
\hline $\arg +++$ & 47 & 28 & - & - \\
\hline+ phe ++ & 1 & - & 2 & - \\
\hline$++l e u+$ & - & - & 4 & 5 \\
\hline$+++\operatorname{ser}$ & - & 150 & - & 161 \\
\hline arg phe ++ & 21 & - & - & - \\
\hline++ leu ser & - & - & - & 8 \\
\hline $\arg ++\operatorname{ser}$ & - & 10 & - & - \\
\hline+ phe leu + & - & - & 1 & $-\}$ \\
\hline $\begin{array}{l}\text { Total no. of } \\
\text { recombinants } \\
\text { per plate }\end{array}$ & 72 & 197 & 10 & 180 \\
\hline $\begin{array}{l}\text { No. of } \\
\text { recombinants } \\
\text { examined }\end{array}$ & 207 & 228 & 213 & 232 \\
\hline
\end{tabular}
Mean frequency of each pair of complementary genotypes

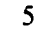

$37 \cdot 5$

$1 \cdot 5$

$4 \cdot 5$

$155 \cdot 5$

$14 \cdot 5$

$5 \cdot 5$

percentage frequencies of the seven pairs of genotypes (or the crossover patterns creating them) in the three crosses were compared for the two possible arrangements of the four markers (Table 5). The data clearly favour the Fig. 1(a) arrangement, which results in a significantly lower frequency of multiple crossover genotypes (an average frequency of quadruple crossovers of $1 \%$ for the Fig. $1(a)$ arrangement compared with $4 \cdot 2 \%$ for the Fig. $1(b)$ arrangement).

The total relative recombination frequencies in each of the four intervals between adjacent markers, and the average for the three crosses (lower part of Table 5) again clearly shows linkage between $\arg -8$ and ser-1. A linkage between $l e u-1$ and ser- 1 is also indicated. These calculations also fit with Fig. $1 a$. 


\section{Table 5. Summary of crosses in Tables 2, 3 and 4}

Values in parentheses are percentages. $a$ Refers to the arrangement of loci in Fig. $1(a)$ and $b$ to the arrangement in Fig. $1(b)$.

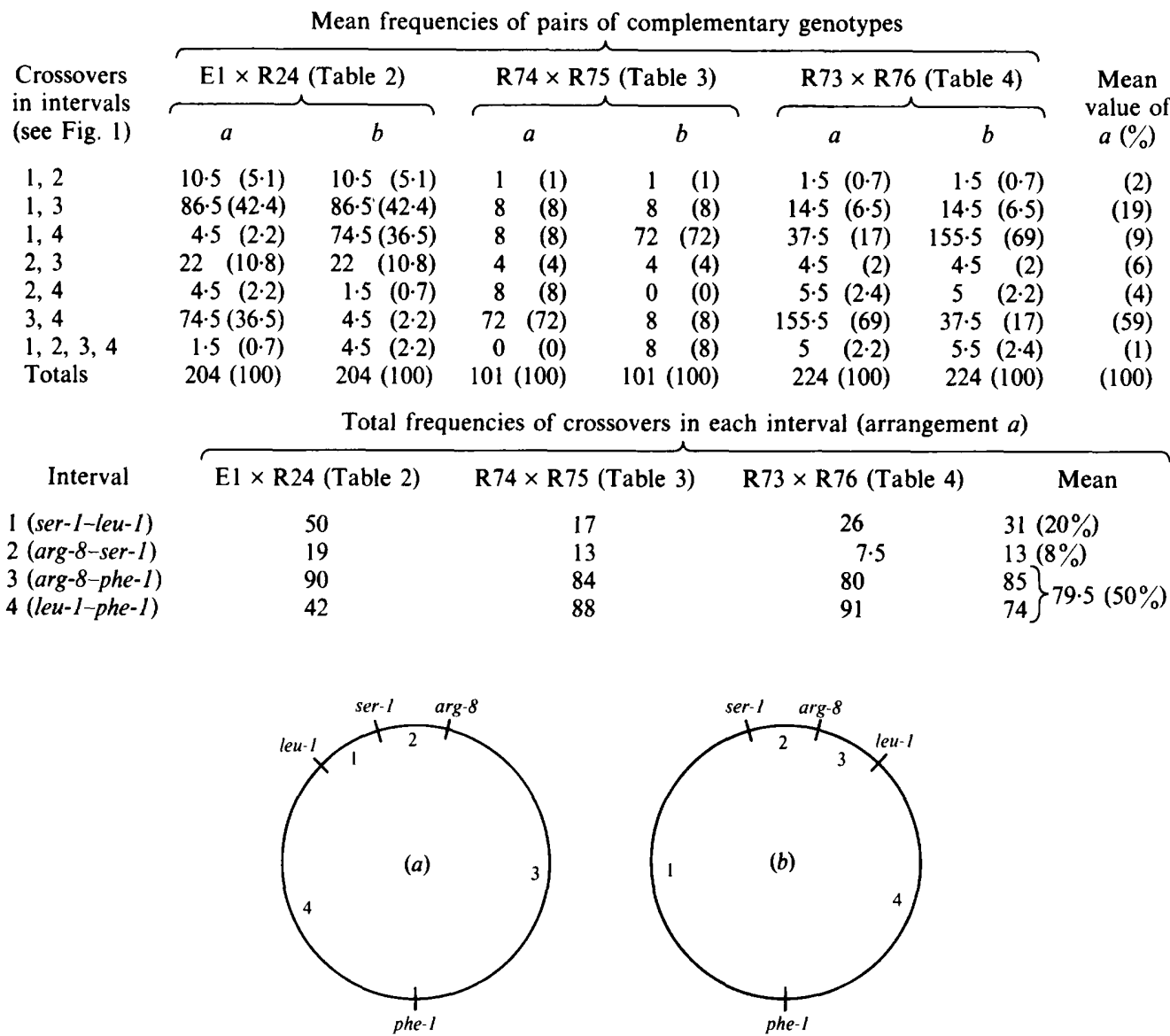

Fig. 1. Two possibilities for the arrangement of four markers from the relative recombination frequencies in the six intervals from Tables 2,3 and 4.

\section{Multi-factor crosses}

After evidence was obtained for a circular arrangement of the four markers, further crosses between various strains and involving additional markers were done. Nearly all of these multiply marked strains were recombinants that had been constructed by matings or by protoplast fusions between various double and triple auxotrophic mutants. Typical multi-factor crosses involved five to seven markers. Spores from mixed cultures of the two strains to be crossed were usually seeded on three or four different media to select for recombination in different map intervals.

After analysis of the recombinants recovered from the selective media, the ratio of each nonselected pair of marker alleles within the arc between the selected markers was determined following the rationale outlined by Hopwood (1967). Of the two possible positions, the one chosen needed the minimum numbers of multiple crossovers for the production of the observed recombinant genotypes. In other cases the most probable position was deduced from consideration of the segregation of the respective allele pair with that of known adjacent markers. Back-crosses involving the same or other known markers in different couplings were performed; these confirmed the correct location of previously mapped mutations. Table 6 shows 
Table 6. Analysis of a multi-factor cross of S. chrysomallus strains 2082 (his-1 pro-1 ura-1) and R25 (arg-2 leu-1 phe-2)

In the diagrams the numbers next to the markers are frequencies of alleles, the numbers between the circles designate map intervals, and the triangles indicate selected alleles.

$$
\begin{array}{ccc}
\text { Crossover } \\
\text { in } \\
\text { Genotypes }
\end{array} \quad \text { No. } \quad \text { intervals }
$$

Selection: his $-I^{+} /$leu- $I^{+}$

$\begin{array}{crl}+++++ & 22 & 2,5 \\ \text { arg }+++ & 48 & 3,5 \\ + \text { phe }++ & 6 & 2,3,4,5 \\ ++ \text { pro }+ & 2 & 2,6 \\ +++ \text { ura } & 21 & 1,5 \\ \text { arg phe }+++ & 16 & 4,5 \\ \text { arg }+ \text { pro }+ & 37 & 3,6 \\ + \text { phe }+ \text { ura } & 8 & 1,3,4,5 \\ \text { arg phe pro }+ & 34 & 4,6 \\ \text { Total } & 194 & \end{array}$

Selection: phe- $I^{+} /$ura $-I^{+}$

$\begin{array}{lrl}+++++ & 7 & 2,5 \\ \text { arg }++++ & 13 & 3,5 \\ \arg \text { leu }++ & 127 & 3,4 \\ \text { arg }++ \text { pro } & 31 & 3,6 \\ + \text { leu his }+ & 1 & 1,2,4,6 \\ \text { arg leu }+ \text { pro } & 2 & 3,4,5,6 \\ \text { Total } & 181 & \end{array}$

Selection: $\arg -2^{+} /$pro- $1^{+}$

$\begin{array}{crl}+++++ & 2 & 2,5 \\ + \text { leu }++ & 3 & 2,4 \\ +++ \text { ura } & 6 & 1,5 \\ \text { phe leu }++ & 21 & 2,3 \\ + \text { leu }+ \text { ura } & 8 & 1,4 \\ \text { phe leu }+ \text { ura } & 109 & 1,3 \\ + \text { leu his ura } & 1 & 4,6 \\ \text { phe }+ \text { his ura } & 1 & 3,4,5,6 \\ \text { phe leu his ura } & 6 & 3,6 \\ \text { Total } & 161 & \end{array}$

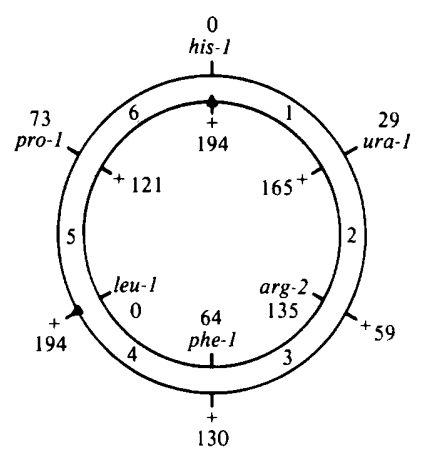

30

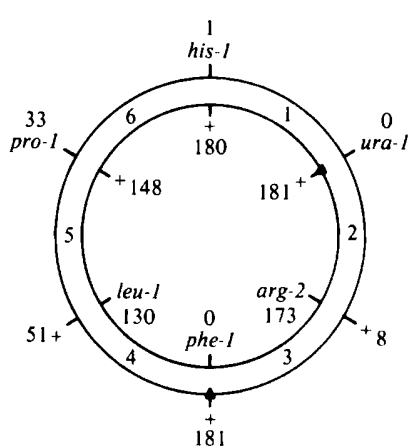

the results of a typical six-factor cross between $S$. chrysomallus strains 2082 (his-1 ura-1 pro-1) and R25 (leu-1 arg-2 phe-1). The analysis of the recombinants from each of the three selective media allowed calculation of the allele ratios of the four non-selected markers. The sequence of markers was the same in all three cases. The most probable arrangement of markers was determined from the map order that gave the lowest number of multiple crossovers (not shown). In all three cases the sequence was the same. 
Table 7. Results of a mating and of a protoplast fusion between $S$. chrysomallus strains $R 26$ (arg-2 his-1 leu-1) and R36 (ade-1 phe-1 pdx-1)

In the diagrams the numbers next to the markers are frequencies of alleles, the numbers between the circles designate map intervals, and the triangles indicate selected alleles.

Selection: ade-1+/his-1+

\begin{tabular}{|c|c|c|c|}
\hline \multicolumn{4}{|c|}{ Selection: ade $-1^{+} /$his $-1^{+}$} \\
\hline Genotypes & Mating & $\begin{array}{l}\text { Protoplast } \\
\text { fusion }\end{array}$ & $\begin{array}{c}\text { Crossover } \\
\text { in } \\
\text { intervals }\end{array}$ \\
\hline++++ & 10 & 25 & 2,5 \\
\hline $\mathrm{leu}+++$ & 1 & 4 & 2,6 \\
\hline$+\arg ++$ & 11 & 27 & 1,5 \\
\hline$+++p d x$ & 105 & 66 & 3,5 \\
\hline leu arg ++ & 2 & 8 & 1,6 \\
\hline$l e u++p d x$ & 17 & 12 & 3,6 \\
\hline leu + phe pdx & 0 & 2 & $3,4,5,6$ \\
\hline$+\quad+$ phe pdx & 4 & 2 & 3,4 \\
\hline$+\arg +p d x$ & 0 & 2 & $1,2,3,5$ \\
\hline+ arg phe + & 0 & 2 & 1,4 \\
\hline Total & 150 & 150 & \\
\hline
\end{tabular}

\begin{tabular}{|c|c|c|c|c|}
\hline & \multicolumn{4}{|c|}{ Mating } \\
\hline & $\mathrm{leu}^{+}$ & leu & $p d x^{+}$ & $p d x$ \\
\hline $\arg ^{+}$ & 119 & 18 & 11 & 126 \\
\hline \multirow[t]{2}{*}{$\arg$} & 11 & 2 & 13 & 0 \\
\hline & \multicolumn{2}{|c|}{ not adjacent } & \multicolumn{2}{|c|}{ adjacent } \\
\hline
\end{tabular}

\begin{tabular}{llrrr} 
& \multicolumn{4}{c}{ Protoplast fusion } \\
\cline { 2 - 5 } $\operatorname{leu}^{+}$ & 93 & 18 & $p d x^{+}$ & $p d x$ \\
$\arg$ & 31 & 8 & 29 & 82 \\
& not adjacent & \multicolumn{2}{c}{ adjacent }
\end{tabular}
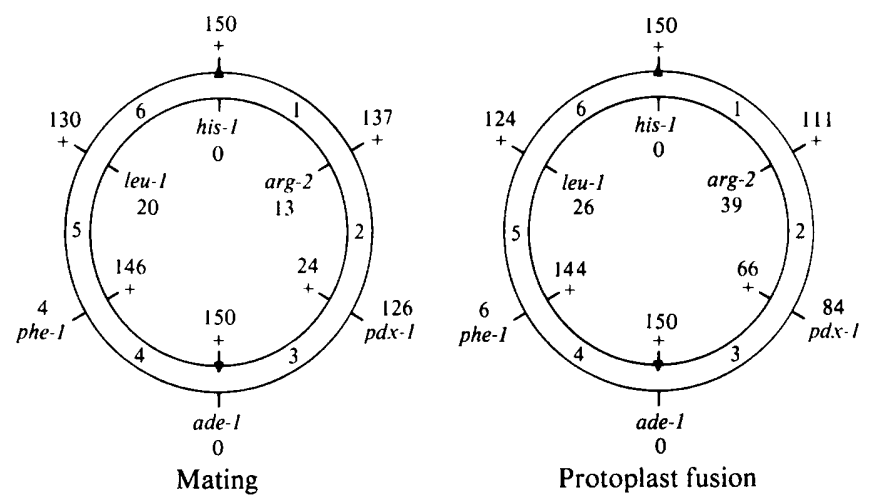

Analysis of crosses by protoplast fusion

Protoplast fusion has been shown to be valuable for mapping studies in several cases (Hopwood \& Wright, 1978; Baltz, 1980; Hranueli et al., 1983; Hopwood et al., 1983). During protoplast fusion an increase in the frequency of multiple crossover genotypes occurs compared to those in corresponding matings. In view of the low sporulation of $S$. chrysomallus and the high recombination frequencies observed during protoplast fusions with this strain (Keller et al., 1983), we tried to apply this technique for mapping studies in multi-factor crosses. Table 7 illustrates the results of crosses based on mating and protoplast fusion between $S$. chrysomallus strains R26 (leul-arg-2 his-1) and R36 (phe-1 ade-1 pdx-1). Protoplast fusion clearly yielded more different genotypes than obtained in a mating, and these belonged to the rare classes, as expected. There was also a significant increase in frequency of crossing over in the different intervals (particularly between his-l arg-2) which leads to the allele ratios being closer to $50: 50$ in the protoplast fusion than in the mating. Similar effects were described by Hopwood et al. (1983) in protoplast fusions with Streptomyces lividans. The data allow the position of an unknown marker in this cross (say arg-2) to be mapped by consideration of its co-segregation 


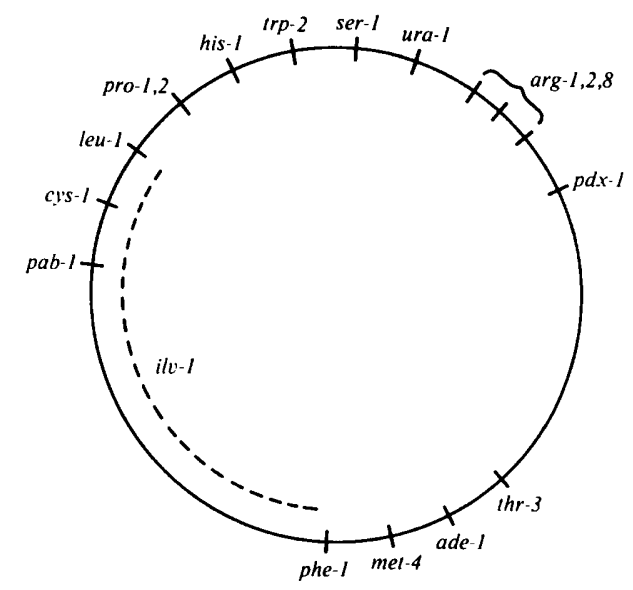

Fig. 2. Arrangement of various marker loci on the genetic map of $S$. chrysomallus. The $i l v-l$ marker has only been mapped between the phe-l and leu-l loci.

with other loci. The $2 \times 2$ tables for both mating and protoplast fusion clearly indicate a location of the arg-2 mutation near to $p d x-1$. Thus, protoplast fusion appears to be a useful technique for mapping studies. However, several protoplast fusion crosses yielded results contradictory to those obtained in conventional matings. In such crosses certain alleles (not always the same ones) appeared to be over-represented, leading to a false allele ratio and hence to a different position on the genetic map. We found earlier (Keller et al., 1983) that actinomycin production has some negative influence on the regeneration of antibiotic non- or low-producers when fused with actinomycin producers. Apparently this effect played a role in such protoplast fusions, because the effects described were always observed when there was strong actinomycin synthesis in the regeneration plates (results not shown). That such effects were not observed in matings may be due to the fact that actinomycin production was very low on MM but was high on modified R2 medium, especially when yeast extract was present. These findings led to problems in using the results of protoplast fusions for mapping purposes with mutants showing increased actinomycin synthesis on modified R2. Therefore, protoplast fusions were mostly performed for strain constructions (up to $70 \%$ recombinants in non-selective conditions), or in rare cases (with actinomycin low-producers) for confirmation of data obtained by matings.

\section{The genetic map, linkage and fertility of $S$. chrysomallus}

As a result of about 70 crosses between various mutants of $S$. chrysomallus, a linkage map could be constructed (Fig. 2). Although the relative map distances between most markers could not be determined precisely (because most crosses were multi-factor crosses analysed by the allele-ratio method), we obtained evidence for the arrangement presented by several semiquantitative observations made during various multi-factor crosses. From the numbers of colonies on selective media and the segregation of pairs of non-selected alleles with those of the four markers in Fig. 1, it was possible to show linkage with the four known markers. Furthermore, some parental marker pairs almost always segregated together (e.g. phe-l and ade- 1 or cys- 1 and leu- 1 ). It was therefore assumed that they were closely linked. Moreover, in a variety of crosses, selection for short intervals resulted in an increase in the proportion of heterokaryons (often also detectable by their smaller colony size). (This effect made it possible to perform complementation tests between independently isolated mutations with identical requirements, as described by Hopwood (1967), in order to see whether they were allelic or not.) Thus, the appearance of heterokaryons at a higher frequency indicated that the two loci for which selection was made were closer to each other than other loci for which the selection gave no heterokaryons or low frequencies of heterokaryons. 


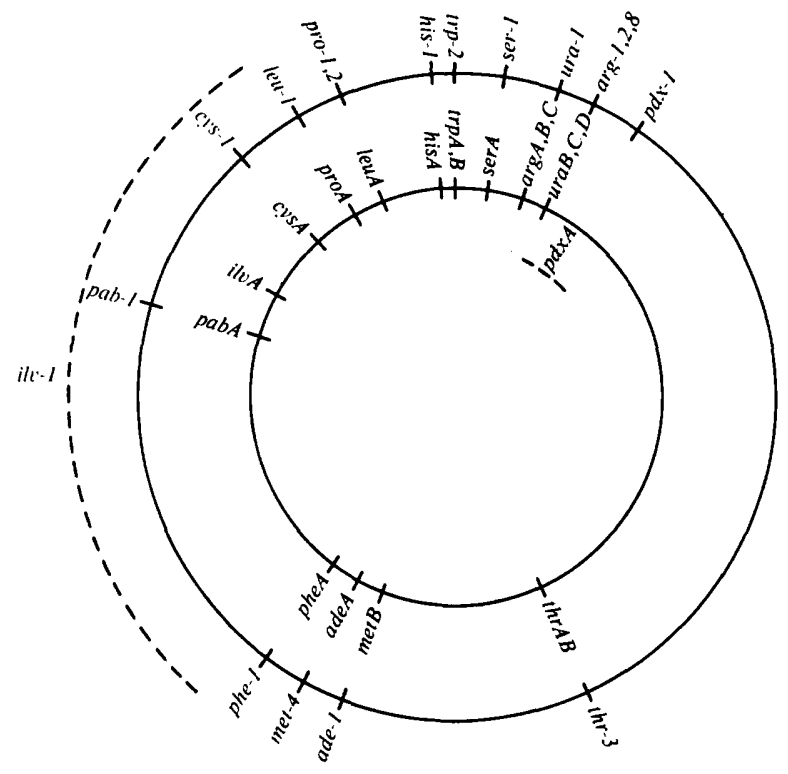

Fig. 3. Comparison of the linkage maps of $S$. coelicolor (inner circle) and $S$. chrysomallus (outer circle). Map intervals in S. chrysomallus have been drawn as in S. coelicolor (Hopwood et al., 1973). Note that the sequences ura-1-arg-1,2,8, leu-1-pro-1,2 and ade-1-met-4 are different in each strain.

Our data revealed only a few markers closely linked to phe-1. The majority of mutations mapped in the region between leu- 1 and arg-1,2,8. In all relevant crosses performed, the interval between phe-I and the pab-1-cys-1-leu-1 region was large. However, the intervals his-1-phe-1 and arg-1,2,8-phe-1 appeared to be significantly larger. The markers ade-1, met-4 and thr-3 mapped rather closely to the phe- 1 locus and it was therefore concluded that these four markers lay in a region of the chromosome significantly distant from that of the majority of mutations.

Attempts were made to increase the recombination frequencies in matings between various mutants of $S$. chrysomallus by the introduction of plasmid pIJ303. This plasmid has been reported to promote chromosomal transfer in matings of $S$. lividans and $S$. coelicolor (Kieser et al., 1982; Hopwood et al., 1983). However, in S. chrysomallus, pIJ303 had no effect either in increasing the recombination frequencies in matings, or in altering the spectrum of various genotypes among the recombinant progeny when compared to crosses performed with the corresponding plasmid-free strains. The plasmid itself was found in $50-60 \%$ of the recombinant progeny, as judged from their thiostrepton resistance phenotype; thus the lack of enhanced fertility was not due to a failure of plasmid transfer. Genetic analysis in $S$. chrysomallus therefore had to be performed under low fertility conditions of $10^{-9}-5 \times 10^{-6}$. The reason for this high variation of recombination frequency in matings of $S$. chrysomallus is still unknown. Previous data obtained with $S$. lividans (Hopwood et al., 1983) revealed that the rate of chromosomal transfer in this strain is determined by the plasmid status of the parents (e.g. recombination frequencies differed by a factor of 100 in SLP2 ${ }^{+} \times \mathrm{SLP}_{2}-$ and SLP2 ${ }^{+} \times \mathrm{SLP}^{+}$matings). The possibility cannot be ruled out that such 'entry disadvantage', due to the presence of native plasmid(s), may play a role in $S$. chrysomallus matings.

\section{DISCUSSION}

The results presented here reveal a circular linkage map for Streptomyces chrysomallus. Similar linkage groups have been described previously for $S$. coelicolor A3(2) (Hopwood, 1965) and a series of other streptomycetes (Friend \& Hopwood, 1971; Coats \& Roeser, 1971; Alačević et al., 1973; Baumann et al., 1974; Hopwood et al., 1983). The analysis of haploid recombinants recovered from crosses by matings, and to a limited extent from protoplast fusions, proved to be 
useful for mapping. The appearance of heterokaryons did not disturb the analysis because their numbers were usually low. Although relative map distances between four markers could be determined in a trio of four-factor crosses according to the procedure of Baumann et al. (1974), the linkage relations of all other markers were only roughly analysed, by consideration of their positions relative to other loci, and from their segregational behaviour in respect of the four known markers. The appearance of heterokaryons on certain selective media was in most cases a good indicator of closely linked selected markers, and so a linkage map could be constructed (Fig. 2). On comparing this genetic map with that of $S$. coelicolor, the genetically best investigated streptomycete (Hopwood et al., 1973), and assuming the identity in the two organisms of the loci considered, a strong conservation of gene sequences is evident (Fig. 3).

The low fertility in $S$. chrysomallus did not severely hamper its genetic analysis. The apparent fertility $\left(10^{-9}-5 \times 10^{-6}\right)$ was highly variable, but was generally lower than that reported for IF $\times$ IF $\left(\mathrm{SCPl}^{+} \times \mathrm{SCP1}^{+}\right)$crosses in $S$. coelicolor (Vivian \& Hopwood, 1970), or SRP $1{ }^{+} \times$SRP $1{ }^{+}$crosses in Streptomyces rimosus (Friend \& Hopwood, 1971 ; Friend et al., 1978). Covalently closed circular DNA could not be detected by physical detection methods in $S$. chrysomallus, and no evidence was obtained that the particular strains used in this study showed an enhanced fertility, i.e. the fertility of a strain varied from cross to cross. Furthermore, $S$. chrysomallus did not display a significantly increased chromosomal transfer when harbouring the plasmid pIJ303, indicating a difference from the streptomycetes of the $S$. coelicolor $/ S$. lividans group. Neither plasmid pIJ303 nor pIJ211 (Kieser et al., 1982) induced pock formation even in well-sporulating strains of $S$. chrysomallus (not shown), and it is possible that this lack of expression of the $\mathrm{Ltz}^{+}$phenotype was due to the presence of a still unknown native plasmid in the organism. However, the finding that these plasmids replicated and expressed their antibiotic resistance in $S$. chrysomallus makes this strain suitable for gene cloning. Thus, the data presented provide a good background of genetics for future work on actinomycin synthesis.

We are grateful to Professor D. A. Hopwood, Norwich, for valuable comments on the manuscript and for providing us with plasmids pIJ303 and pIJ211. We also thank Mr S. J. Lucania of E. J. Squibb and Sons, Princeton, New Jersey, for a sample of thiostrepton.

This work was supported by the Deutsche Forschungsgemeinschaft (Sfb9, D5).

\section{REFERENCES}

Alačević, M., Strašek-Vešligaj, M. \& Sermonti, G. (1973). The circular linkage map of Streptomyces rimosus. Journal of General Microbiology 77, 173-185.

BALTZ, R. H. (1980). Genetic recombination by protoplast fusion in Streptomyces. Developments in Industrial Microbiology 21, 43-54.

BaumanN, R., Hütter, R. \& Hopwood, D. A. (1974). Genetic analysis in a melanin producing streptomycete, Streptomyces glaucescens. Journal of General Microbiology 81, 463-474.

Chater, K. F., Hopwood, D. A., Kieser, T. \& Thompson, C. J. (1982). Gene cloning in Streptomyces. Current Topics in Microbiology and Immuno$\log y$ 96, 69-95.

COATS, J. H. \& RoEser, J. (1971). Genetic recombination in Streptomyces bikiniensis var. Zorbonensis. Journal of Bacteriology 105, 880-885.

Delić, V., Hopwood, D. A. \& Friend, E. J. (1970). Mutagenesis by $N$-methyl- $N^{\prime}$-nitro- $N$-nitrosoguanidine (NTG) in Streptomyces coelicolor. Mutation Research 9, 167-182.

Friend, E. J. \& Hopwood, D. A. (1971). The linkage map of Streptomyces rimosus. Journal of General Microbiology' 68, 187-197.

Friend, E. J., Warren, M. \& Hopwood, D. A. (1978). Genetic evidence for a plasmid controlling fertility in an industrial strain of Streptomyces rimosus. Journal of General Microbiology 106, 201-206.
Hopwood, D. A. (1965). A circular linkage map in the actinomycete Streptomyces coelicolor. Journal of Molecular Biology 12, 514-516.

HopwOOD, D. A. (1967). Genetic analysis and genome structure in Streptomyces coelicolor. Bacteriological Reviews 31, 373-403.

HoPwOOD, D. A. (1972). Genetic analysis in microorganisms. Methods in Microbiology 7B, 29-158.

HoPwOOD, D. A. \& WRIGHT, M. H. (1978). Bacterial protoplast fusion: recombination in fused protoplasts of Streptomyces coelicolor. Molecular and General Genetics 162, 301-317.

Hopwood, D. A., Chater, K. F., Dowding, J. E. \& Vivian, A. (1973). Advances in Streptomyces coelicolor genetics. Bacteriological Reviews 37, 371405.

Hopwood, D. A., Kieser, T., Wright, H. M. \& BibB, M. J. (1983). Plasmids, recombination and chromosome mapping in Streptomyces lividans 66. Journal of General Microbiology 129, 2257-2269.

Hranueli, D., Pigac, J., Smokvina, T. \& Alačević, M. (1983). Genetic interactions in Streptomyces rimosus mediated by conjugation and by protoplast fusion. Journal of General Microbiology 129, 14151422.

KatZ, E. (1967). Actinomycin. In Antibiotics, vol. II, pp. 276-341. Edited by D. Gottlieb \& P. D. Shaw. New York: Springer Verlag. 
KELLER, U. (1984). Acyl pentapeptide lactone synthesis in actinomycin-producing streptomycetes by feeding with structural analogs of 4-methyl-3hydroxyanthranilic acid. Journal of Biological Chemistry 259, 8226-8231.

Keller, U., Pöschmann, S., Krengel, K., KleinKauf, H. \& Kraepelin, G. (1983). Studies of protoplast fusion in Streptomvces chrysomallus. Journal of General Microbiology 129, 1725-1731.

Keller, U., Kleinkauf, H. \& Zocher, R. (1984). 4-Methyl-3-hydroxyanthranilic acid activating enzyme from actinomycin-producing Streptomyces chrysomallus. Biochemistry 23, 1479-1484.

KiESER, T., HopWOOD, D. A., Wright, H. M. \& THOMPSON, C. J. (1982). pIJl01, a multi-copy broad host-range Streptomyces plasmid: functional analysis and development of DNA cloning vectors. Molecular and General Genetics 185, 223-238.

OKanishi, M., Suzuki, K. \& Umezawa, H. (1974). Formation and reversion of streptomycete protoplasts: cultural conditions and morphological study. Journal of General Microbiology 80, 389-400.
Pridham, T. G., Anderson, P., Foley, C., LindenFelser, L. A., Hesseltine, C. W. \& Benedict, R. G. $(1956 / 57)$. Selection of media for maintenance and taxonomic study of Streptomyces. Antibiotics Annual, 947-953.

RudD, B. A. M. \& Hopwood, D. A. (1979). Genetics of actinorhodin biosynthesis by Streptomyces coelicolor A3(2). Journal of General Microbiology 114, 35-43.

RudD, B. A. M. \& Hopwood, D. A. (1980). A pigmented mycelial antibiotic in Streptomyces coelicolor: control by a chromosomal gene cluster. Journal of General Microbiology 119, 333-340.

Thompson, C. J., Ward, J. M. \& Hopwood, D. A. (1980). DNA cloning in Streptomyces: resistance genes from antibiotic-producing species. Nature, London 286, 525-527.

Vivian, A. \& HopwOOD, D. A. (1970). Genetic control of fertility in Streptomyces coelicolor A3(2): the IF fertility type. Journal of General Microbiology 64, 101-117. 